\title{
Storage stability of jackfruit (Artocarpus heterophylus) power packaged in aluminium laminated polyethylene and metallized co-extruded biaxially oriented polypropylene during storage
}

\begin{abstract}
Total colour difference $(\Delta \mathrm{E})$, rates of adsorbed moisture and sensory attributes of drum-dried jackfruit powder packaged in aluminium laminated polyethylene (ALP) and metallized coextruded biaxially oriented polypropylene (BOPP/MCPP) pouches stored at accelerated storage $\left(38{ }^{\circ} \mathrm{C}\right.$, with $50 \%, 75 \%$ and $90 \%$ relative humidity (RH)) were determined over 12 weeks period. The changes in total colour followed zero order reaction kinetics. Packaging materials, storage temperature and RH values significantly $(p<0.05)$ influenced the rates of adsorbed moisture of jackfruit powder. There was a significant $(p<0.05)$ decrease in the intensities of the fruity odour, taste and increase in the lumpiness of the jackfruit powder stored at $38{ }^{\circ} \mathrm{C}$ with $90 \% \mathrm{RH}$. The shelf life of jackfruit powder stored at $38{ }^{\circ} \mathrm{C}$ and $90 \% \mathrm{RH}$ was limited by overall acceptability and the intensity of fruity odour, taste and lumpiness at week 8 of storage. Jackfruit powder stored at $28{ }^{\circ} \mathrm{C}$ remained stable and acceptable throughout the storage period for all RH values. The powder packaged in ALP significantly $(\mathrm{p}<0.05)$ reduced total colour change, rates of adsorbed moisture, lumpiness intensity of jackfruit powder and was rated higher in terms of overall acceptability over BOPP/MCPP. Results of this study suggested that ALP packaging with storage conditions of $28{ }^{\circ} \mathrm{C}$ and $\mathrm{RH}$ less than $75 \%$ was better suited for keeping jackfruit powder.
\end{abstract}

Keyword: Jackfruit (Artocarpus heterophyllus) powder, Accelerated storage, Total colour difference, Adsorbed moisture rates and sensory attributes 